TI 2014-140/VIII

Tinbergen Institute Discussion Paper

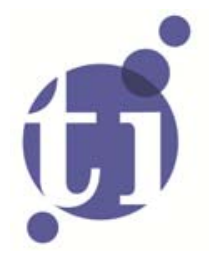

tinbergen institute

\title{
Third-degree Price Discrimination in the Presence of Congestion Externality
}

Achim I. Czerny'

Anming Zhang ${ }^{2}$

1 Faculty of Economics and Business Administration, VU University Amsterdam, and Tinbergen Institute, the Netherlands;

${ }^{2}$ The University of British Columbia, Canada. 
Tinbergen Institute is the graduate school and research institute in economics of Erasmus University Rotterdam, the University of Amsterdam and VU University Amsterdam.

More TI discussion papers can be downloaded at http://www.tinbergen.nl

Tinbergen Institute has two locations:

Tinbergen Institute Amsterdam

Gustav Mahlerplein 117

1082 MS Amsterdam

The Netherlands

Tel.: +31(0)205251600

Tinbergen Institute Rotterdam

Burg. Oudlaan 50

3062 PA Rotterdam

The Netherlands

Tel.: +31(0)10 4088900

Fax: $+31(0) 104089031$

Duisenberg school of finance is a collaboration of the Dutch financial sector and universities, with the ambition to support innovative research and offer top quality academic education in core areas of finance.

DSF research papers can be downloaded at: http://www.dsf.nl/

Duisenberg school of finance

Gustav Mahlerplein 117

1082 MS Amsterdam

The Netherlands

Tel.: +31(0)20 5258579 


\title{
Third-degree Price Discrimination in the Presence of Congestion Externality
}

\author{
Achim I. Czerny*and Anming Zhang ${ }^{\dagger}$
}

October 22,2014

\begin{abstract}
This paper analyzes third-degree price discrimination of a monopoly airline in the presence of congestion externality when all markets are served. The model features the business-passenger and leisure-passenger markets where business passengers exhibit a higher time valuation, and a less price-elastic demand, than leisure passengers. Our main result is the identification of the time-valuation effect of price discrimination, which can work in the opposite direction as the well-known output effect on welfare. This time-valuation effect clearly explains why discriminating prices can improve welfare even when this is associated with a reduction in aggregate output.

Keywords: Price discrimination; congestion; time valuation; monopoly; airline. JEL: D42, L93.
\end{abstract}

${ }^{*}$ Corresponding author. VU University Amsterdam, Department of Spatial Economics, and Tinbergen Institute, a.i.czerny@vu.nl, +31-(0)20-5986218.

†University of British Columbia, Sauder School of Business. 


\section{Introduction}

This paper investigates monopoly third-degree price discrimination in the presence of congestion externality, focusing on airline markets when all markets are served. Airlines are a frequently used example for markets where price discrimination is prevalent (e.g., Borenstein, 1985; Dana, 1999a/1999b; Cowan, 2007). The analysis is motivated by the observation that airline markets exhibit congestion effects that can lead to interdependencies between the business-passenger and leisure-passenger demands (e.g., Zhang and Czerny, 2012). The main objective is to investigate how the demand interdependencies affect discriminating prices and the evaluation of price discrimination from the social viewpoint.

To see how congestion can lead to demand interdependence, consider two passenger groups, namely, business and leisure passengers. The two groups are different in three aspects: i) business passengers have a greater value of time than leisure passengers (e.g., Morrison, 1987; Morrison and Winston, 1989; USDOT, 1997; Pels et al., 2003); ii) business passengers often exhibit a lower price elasticity of demand than leisure passengers; and iii) business passengers book their flights relatively late, which allows airlines to price-discriminate between the business and leisure passengers by advance-purchase rebates (e.g., Gale and Holmes, 1993; Dana, 1998; Stavins, 2001; Lazarev, 2013). ${ }^{1}$ Since capacity (runways, air navigation and traffic control, etc.) is usually limited (especially at hub airports), passengers not only pay for a ticket but also experience airport delays (e.g., Daniel, 1995; Brueckner, 2002; Mayer and Sinai, 2003; Zhang and Zhang, 2006; Morrison and Winston, 2007). The "full fare" of traveling is, therefore, composed of the ticket price and congestion costs, with the latter being further determined by the

product of the per-passenger delay and passengers' values of time. At the demand equilibrium, the marginal utility of traveling is equal to the full fare for every passenger. Then an increase in the quantity of leisure or business passengers increases the delay and hence the full fare to the other group, thereby reducing the latter's demand. This illustrates the demand interdependence between the two groups. 
Many useful insights on the effects of monopolistic price discrimination on prices and social welfare have been derived until now. A central result is that relative to the uniform pricing regime, price discrimination is often associated with a price increase in the "strong market" (corresponding to the business market in our setting) and a price reduction in the "weak market" (corresponding to the leisure market) (e.g., Pigou, 1920; Robinson, 1933; Holmes, 1989; Aguirre et al., 2010). Hausman and MacKieMason (1988) consider a monopolist with a valid patent on innovation and show that economies of scale and learning may reduce discriminatory prices in each market relative to uniform prices, while Layson (1994) finds that price discrimination can also raise prices in all markets under these conditions. Nahata et al. (1990) consider independent demands and use specific functional forms to show that monopoly prices can move in the same direction as a result of price discrimination, while generally this cannot be true when each market's profits are concave in own prices. Layson (1998) finds that either interdependent demands with sufficient demand substitution between the markets or falling marginal cost are required for prices to move in the same direction.

In terms of welfare, price discrimination can have two effects: i) it reduces welfare because, with price discrimination, marginal utilities are no longer the same between consumers (the so-called "misallocation effect"); and ii) it changes aggregate quantities (the "output effect"). Schmalensee (1981) showed that a necessary condition for price discrimination to improve welfare is a "positive" output effect - the aggregate quantity rises relative to that under uniform pricing. Varian (1985) and Schwartz (1990) showed that Schmalensee's result also holds for interdependent demands and decreasing marginal costs, respectively. Note that a crucial assumption underlying Varian's analysis is that indirect utilities are convex in prices. Whether the output effect is positive or negative depends on the curvature of demand functions, which have been analyzed by Robinson (1933), Schmalensee (1981), Holmes (1989) and Stole (2007) for independent demands. More recently, by assuming independent demands as well, Aguirre et al. (2010) derived conditions for the curvature of demand functions that are informative with respect to the welfare effect of price discrimination. Cowan (2013) analyzed the 
welfare and output effects of price discrimination for the special case of parallel inverse demand functions. That monopoly third-degree price discrimination can be beneficial for consumers has recently been shown by Cowan (2012).

The present paper complements and extends the literature on monopoly third-degree price discrimination, by providing a detailed analysis of uniform vs. discriminating prices when demands are interdependent because of congestion externalities. ${ }^{2}$ We find that the existing result - that price discrimination results in a price increase in the strong market and a price reduction in the weak market - continues to hold as long as the demand interdependence is sufficiently small or the time values of business and leisure passengers are similar. If the time valuations are sufficiently distinct, price discrimination can however lead to a price increase in both markets. ${ }^{3}$ The intuition is based on the observation that an increase in the leisure price reduces the quantity of leisure passengers, which in turn will, by reducing congestion, increase service quality for business passengers.

We further find that social welfare can be increased by price discrimination even if the aggregate quantity is reduced. This is because the "time-valuation effect," which we will identify in this paper and works in the opposite direction to the output effect, dominates the output effect when the "marginal" time valuation (defined as the average time valuation of incremental passengers) is sufficiently low relative to the average time valuation. Basically, the carrier's incentive to internalize the congestion costs imposed on its passengers ("self internalization") depends on the marginal time valuations. On the other hand, the first-best price is uniform and is set to internalize the part of congestion costs that are external to passengers, which is based on the average time valuation. Given that the marginal time valuation is low relative to the average time valuation (which follows under plausible assumptions made in the paper), the carrier's incentive for self-internalization when it is constrained to charge a uniform price is too low from the social viewpoint, resulting in an excessively high aggregate passenger volume and hence excessive congestion. That is, the uniform monopoly price is socially too low in this case. Price discrimination, although it cannot achieve the first-best outcome, 
can increase welfare by reducing aggregate quantity and hence congestion costs, which can overcome the harmful misallocation and output effects of discrimination. As to be seen in Section 3 below, the time-valuation effect won't exist if the business and leisure passengers have the same time valuation. The monopolist's underincentive to reduce congestion is analogous to the underincentive to increase quality when the marginal valuation of quality is less than the average valuation as shown by Spence (1975) and Sheshinski (1976). ${ }^{4}$

Using linear functional forms and ad hoc assumptions to capture negative consumption externalities, Adachi (2005) showed that price discrimination can increase social welfare when aggregate outputs are reduced. In a parallel but independent study, Chen and Schwartz (2013) analyze the welfare effects of third-degree differential pricing when costs of service differ across consumer groups, while demands are equally elastic. They identify mild demand curvature conditions that ensure welfare increasing differential prices. ${ }^{5}$ Since the congestion costs differ for business and leisure passengers in the present paper, these studies are closely related. The contribution of the present paper is to identify, clearly and in a transparent manner, the effects that are responsible for the welfare changes of third-degree price discrimination in the presence of congestion externalities in a general and micro founded framework. Finally, this paper contributes to the transport economics literature on congestion by developing an integrated framework that incorporates congestion and carrier price discrimination. While airline markets are a frequently used example for markets where price discrimination is prevalent, this literature typically abstracts away from price discrimination and concentrates on uniform

prices. ${ }^{6}$ Our study is, to our best knowledge, the first paper that captures facility congestion and carrier price discrimination behavior.

\section{The Model}

Consider an origin-destination (OD) air travel market. Passengers are partitioned in two groups: the business passengers and the leisure passengers. Let $q_{B}$ denote the 
business-passenger quantity and $q_{L}$ the leisure-passenger quantity (to be simply referred to as the business and leisure quantities, respectively). The business passengers' utility (gross travel benefit) is $B_{B}\left(q_{B}\right)$, and the leisure passengers' utility is $B_{L}\left(q_{L}\right)$. The utility functions are strictly concave: $B_{x}^{\prime}\left(q_{x}\right)>0$ and $B_{x}^{\prime \prime}\left(q_{x}\right)<0$ for $x=B, L$.

There is a monopoly carrier that uses airports to provide service in the OD market. Either the origin airport or the destination airport (or both) have a limited capacity in, for example, runways. A consequence of the limited capacity is that passengers incur airport congestion delays. The average delay depends on aggregate quantity $q \equiv q_{B}+q_{L}$ in the market, and is denoted as $C(q)$ with $C^{\prime}(q)>0$ and $C^{\prime \prime}(q) \geq 0$. Passengers cannot affect $C$, the average delay, as individuals are atomistic. While $C$ is the same for all passengers, the delay costs depend on passenger types: the business passengers exhibit a higher value of time than the leisure passengers. Denoting the passengers' time valuations as $v_{x}$, then their delay costs are $v_{x} C(q)$ with $v_{B} \geq v_{L}(\geq 0)$.

Denote the ticket price charged to business passengers as $p_{B}$, and the ticket price charged to leisure passengers as $p_{L}$ (in the following, we refer to "ticket prices" simply as "prices"). Taking $p_{x}$ and average delays as given, passengers maximize their net benefit leading to the following optimality conditions:

$$
B_{B}^{\prime}\left(q_{B}\right)-\left(p_{B}+v_{B} C\right)=0 \text { and } B_{L}^{\prime}\left(q_{L}\right)-\left(p_{L}+v_{L} C\right)=0
$$

Conditions (1) mean that for each passenger type, its marginal (gross) benefit $B_{x}^{\prime}$ equals its "full fare," which is taken for simplicity as the sum of price and congestion delay cost. These two equations jointly determine the passenger demands in full fares. Denoting the full fares as $\eta_{x} \equiv p_{x}+v_{x} C$ the strict concavity of passenger benefit functions further implies a unique (equilibrium) demand function for each passenger type $q_{x}\left(\eta_{x}\right)$, with $q_{x}^{\prime}\left(\eta_{x}\right)=1 / B_{x}^{\prime \prime}<0$ and $x=B, L$. Clearly, these two (full-fare) demands are independent, and are downward-sloping in own full fares.

To economize notation, denote the business passengers' time valuation as $v$ and the leisure passengers' as $\alpha v$ with $\alpha \in[0,1]$. Note that $v=0(v>0$, respectively) indicates independence (interdependence, respectively) between the business and leisure 
demands. Conditions (1) can be considered as a system of equations that implicitly determines inverse business demand and inverse leisure demand functions, which can be rewritten as

$$
g_{B} \equiv B_{B}^{\prime}-\left(p_{B}+v C\right)=0 \text { and } g_{L} \equiv B_{L}^{\prime}-\left(p_{L}+\alpha v C\right)=0 .
$$

The Jacobian of the system of inverse demands, can then be derived as

$$
\left(\begin{array}{cc}
\partial g_{B} / \partial q_{B} & \partial g_{B} / \partial q_{L} \\
\partial g_{L} / \partial q_{B} & \partial g_{L} / \partial q_{L}
\end{array}\right)=\left(\begin{array}{cc}
B_{B}^{\prime \prime}-v C^{\prime} & -v C^{\prime} \\
-\alpha v C^{\prime} & B_{L}^{\prime \prime}-\alpha v C^{\prime}
\end{array}\right)
$$

where the matrix on the RHS is easily seen to be negative definite. Thus, a unique solution for the (equilibrium) demands in prices exists as well. Implicitly determined by (2), such demands are denoted as

$$
q_{B}=D^{B}\left(p_{B}, p_{L}\right) \text { and } q_{L}=D^{L}\left(p_{B}, p_{L}\right),
$$

with the aggregate demand being $D \equiv D^{L}+D^{B}$.

To derive the effect of changes in business prices on demands $D^{B}$ and $D^{L}$, substitute $q_{x}$ in $(2)$ with $D^{x}$, totally differentiate the resulting equations with respect to $p_{B}$ and apply Cramer's rule. These yield

$$
D_{B}^{B} \equiv \frac{\partial D^{B}\left(p_{B}, p_{L}\right)}{\partial p_{B}}=\frac{B_{L}^{\prime \prime}-\alpha v C^{\prime}}{\Omega}<0 \text { and } D_{B}^{L} \equiv \frac{\partial D^{L}\left(p_{B}, p_{L}\right)}{\partial p_{B}}=\frac{\alpha v C^{\prime}}{\Omega}>0,
$$

where $\Omega$ is the determinant of matrix (3) and is positive due to its negative definiteness:

$$
\Omega \equiv B_{B}^{\prime \prime} B_{L}^{\prime \prime}-\left(B_{L}^{\prime \prime}+B_{B}^{\prime \prime} \alpha\right) v C^{\prime}>0
$$

Inequalities (5) illustrate the interdependence of demands (4): while the business demand decreases in the business price, the leisure demand increases in the business price. The latter holds true because the fall in business quantities reduces congestion delays and hence the leisure full-fare, which in turn stimulates the leisure demand. The relationships in (5) further imply

$$
D_{B} \equiv \frac{\partial\left(D^{B}+D^{L}\right)}{\partial p_{B}}=\frac{B_{L}^{\prime \prime}}{\Omega}<0 .
$$


Thus, an increase in the business price unambiguously reduces the aggregate demand. Similarly, a change in $p_{L}$ has the following effects:

$$
D_{L}^{B} \equiv \frac{\partial D^{B}\left(p_{B}, p_{L}\right)}{\partial p_{L}}=\frac{v C^{\prime}}{\Omega}>0 \text { and } D_{L}^{L} \equiv \frac{\partial D^{L}\left(p_{B}, p_{L}\right)}{\partial p_{L}}=\frac{B_{B}^{\prime \prime}-v C^{\prime}}{\Omega}<0,
$$

and

$$
D_{L} \equiv \frac{\partial\left(D^{B}+D^{L}\right)}{\partial p_{L}}=\frac{B_{B}^{\prime \prime}}{\Omega}<0 .
$$

While an increase in the leisure price reduces leisure demands, it increases business demands; furthermore, it reduces the aggregate demand.

So far, the demand analysis takes the business and leisure prices as independent variables. For the regime of uniform pricing however, $p_{B}=p_{L} \equiv p$ with $p$ denoting the uniform price. Consequently, a change in the uniform price simultaneously alters both the business and leisure prices. Using the preceding results, the demand effects of the uniform price can be derived as

$$
\begin{aligned}
& \frac{\partial D^{B}}{\partial p}=D_{B}^{B}+D_{L}^{B}=\frac{B_{L}^{\prime \prime}+(1-\alpha) v C^{\prime}}{\Omega}, \\
& \frac{\partial D^{L}}{\partial p}=D_{B}^{L}+D_{L}^{L}=\frac{B_{B}^{\prime \prime}-(1-\alpha) v C^{\prime}}{\Omega}<0,
\end{aligned}
$$

and

$$
\frac{\partial\left(D^{B}+D^{L}\right)}{\partial p}=\frac{B_{B}^{\prime \prime}+B_{L}^{\prime \prime}}{\Omega}<0,
$$

where $(1-\alpha)$ determines the extra cost of delay for types $B$ compared to $L$. Inequalities (11) and (12) indicate that an increase in the uniform price reduces the leisure demand as well as aggregate demand. In contrast, by equation (10) its impact on the business demand consists of two opposing effects: i) a higher price reduces demand; but ii) a smaller aggregate demand (owing to the higher price) lowers the congestion level and hence the full fare faced by business passengers, thereby increasing their demand. Although the net effect is generally ambiguous in sign, an increase in the uniform price can increase the business demand if the business passengers' time valuation is sufficiently greater than the leisure passengers'. These uniform-price results are similar to the ones derived by Czerny and Zhang (2011). 
Having characterized the demand functions, we now examine the supply behavior. With the carrier's operating costs normalized (without loss of generality) to zero, its profit may be written as

$$
\pi\left(p_{B}, p_{L}\right) \equiv p_{B} D^{B}\left(p_{B}, p_{L}\right)+p_{L} D^{L}\left(p_{B}, p_{L}\right)
$$

Under the uniform-price regime, the carrier chooses $p$ to maximize profit, leading to the first-order condition

$$
D+p \cdot\left(D_{p}^{L}+D_{p}^{B}\right)=0
$$

where subscripts again denote partial derivatives, $D_{p}^{x} \equiv \partial D^{x} / \partial p, x=B, L$. The optimal price, $p^{u}$ ( $u$ for "uniform pricing"), is then characterized by (14) and the secondorder condition $\partial^{2} \pi / \partial p^{2}<0$. Under the laissez-faire regime, however, the carrier chooses the business and leisure prices independently. The optimal prices, $p_{B}^{l f}$ and $p_{L}^{l f}(l f$ for "laissez-faire pricing"), are characterized by the first-order conditions $\partial \pi / \partial p_{L}=0$ and $\partial \pi / \partial p_{B}=0$ which can, respectively, be expressed as

$$
D^{L}+p_{L} D_{L}^{L}+p_{B} D_{L}^{B}=0 \text { and } p_{L} D_{B}^{L}+D^{B}+p_{B} D_{B}^{B}=0
$$

To ensure that the carrier charges business passengers with a higher fare relative to leisure passengers, we assume that the business demand is less price elastic than the leisure demand in the sense that the following elasticity condition,

$$
-q_{B}^{\prime} / D^{B}<-q_{L}^{\prime} / D^{L}, \quad \text { (Elasticity condition) }
$$

holds in the carrier optimum in the remainder of the paper (see Appendix A for the derivations). ${ }^{7}$ This condition implies that leisure passengers comprise a higher share of marginal passengers than of inframarginal passengers (i.e., $-q_{L}^{\prime} / q_{L}>-q^{\prime} / q$ ), hence the marginal passengers are not representative, which will be important for our welfare analysis. $^{8}$ 


\section{Effects of Price Discrimination}

A useful tool to analyze price discrimination relative to uniform pricing is the pricedifference constraint..$^{9}$ More specifically, denote $p_{L}$ (the leisure price) as $p$ and substitute $p+\phi$ for $p_{B}$ (the business price). Parameter $\phi$ can be used to analyze the two alternative pricing scenarios in a unifying framework: Uniform pricing is imposed when $\phi=0$, while $\phi>0$ implies (strict) price discrimination. More importantly, the use of $\phi$ allows one to derive the comparative-static relationship between the discriminating prices under price discrimination (referred to as "laissez faire") - where $\phi$ is chosen by the carrier and uniform prices. For example, if an increase in $\phi$ is unambiguously associated with an increase of $p_{x}$, then we know that a change from uniform pricing to laissez-faire will increase the price in market $x$. The situation is illustrated in Figure 1, where laissezfaire implies $\phi=\phi^{l f} .{ }^{10}$ Starting with the uniform price at $\phi=0$, an increase in price discrimination raises the business price while it, respectively, suppresses (dashed lines with $\alpha=0$ and $v=1 / 10$ ) or raises (solid lines with $\alpha=0$ and $v=1 / 2$ ) the leisure price depending on whether time valuations are less or more distinct. The advantage of the price-difference constraint is, therefore, that it provides a unifying framework, which incorporates uniform prices and laissez-faire as special cases. A simple comparativestatic analysis can then be used to compare prices, quantities and welfare.

\section{Figure 1}

\subsection{Prices and aggregate output}

Examine first the effect of price discrimination on prices. For a given price difference $\phi$, the carrier's profit (13) can be rewritten as

$$
\pi(p) \equiv(p+\phi) D^{B}(p+\phi, p)+p D^{L}(p+\phi, p)
$$

The optimal leisure price is characterized by the first-order condition $\pi_{p}^{\prime}=0$ or equivalently,

$$
D+p \cdot\left(D_{L}+D_{B}\right)+\phi \cdot\left(D_{L}^{B}+D_{B}^{B}\right)=0
$$


and the second-order condition $\pi^{\prime \prime}<0 .{ }^{11}$ The effect of price discrimination on the leisure price can be derived by treating $\phi$ as exogenous and totally differentiating (17) with respect to $\phi$, which leads to

$$
\frac{d p_{L}}{d \phi}=-\left(\frac{2 B_{L}^{\prime \prime}+(1-\alpha) v C^{\prime}}{\Omega}+\kappa_{L}(v)\right) / \pi^{\prime \prime},
$$

with $\pi^{\prime \prime}<0$ by the second-order condition, $\Omega>0$ by (6) and

$$
\kappa_{L}(v) \equiv p \cdot\left(D_{L B}+D_{B B}\right)+\phi \cdot\left(D_{L B}^{B}+D_{B B}^{B}\right) .
$$

Whilst $\kappa_{L}$ becomes zero in the case of linear demands in prices, its sign is unknown in general. Rearranging the terms of (18) shows that $d p_{L} / d \phi>0$ when

$$
(1-\alpha) v>-\frac{2 B_{L}^{\prime \prime}+\Omega \kappa_{L}(v)}{C^{\prime}} .
$$

For the linear demands, therefore, condition (20) reduces to

$$
(1-\alpha) v>-\frac{2 B_{L}^{\prime \prime}}{C^{\prime}}(>0) .
$$

The LHS of (21) determines the difference between business and leisure time valuations. (Note that time valuations are the same for all passengers when $\alpha=1$.) Price discrimination will thus increase the leisure price if the time valuations of the two passenger types are sufficiently distinct in the sense that (21) holds. On the other hand, if time valuations are relatively uniform (in the sense that $(1-\alpha) v<-2 B_{L}^{\prime \prime} / C^{\prime}$ ), price discrimination reduces the leisure price. The difference in time valuations is important because this difference determines the scope for an increase in the business price relative to the leisure price that arises from a reduction in the leisure quantity (besides the demand elasticities).

Since

$$
\frac{d p_{B}}{d \phi}=1+\frac{d p_{L}}{d \phi},
$$

a rise in the leisure price (due to price discrimination) will imply an increase in the business price. Furthermore, using (18) and (22) the effect of price discrimination on the business price can be derived as

$$
\frac{d p_{B}}{d \phi}=\left(\frac{2 B_{B}^{\prime \prime}-(1-\alpha) v C^{\prime}}{\Omega}+\kappa_{B}(v)\right) / \pi_{p}^{\prime \prime},
$$


with

$$
\kappa_{B}(v) \equiv p \cdot\left(D_{L L}+D_{L B}\right)+\phi \cdot\left(D_{L L}^{B}+D_{B L}^{B}\right)
$$

Similarly to $\kappa_{L}(v), \kappa_{B}(v)$ is zero when the demands are linear in prices (while its sign is generally unknown). As a result, $d p_{B} / d \phi>0$ for linear demands by noting that the signs for all the other terms on the RHS of (23) are known.

As indicated earlier, the welfare effect of price discrimination depends critically on its impact on aggregate output. The price effects derived above can be used to analyze the effect on aggregate quantities as follows:

$$
\begin{aligned}
\frac{d D}{d \phi} & =D_{L} \frac{d p_{L}}{d \phi}+D_{B} \frac{d p_{B}}{d \phi} \\
& =\left(\left(B_{B}^{\prime \prime}+B_{L}^{\prime \prime}\right) \frac{d p_{L}}{d \phi}+B_{L}^{\prime \prime}\right) / \Omega .
\end{aligned}
$$

The RHS of (25b) will take a negative sign if price discrimination increases the leisure price. This is expected as a positive $d p_{L} / d \phi$ implies a positive $d p_{B} / d \phi$, which together suppress the aggregate demand. Otherwise, the effect of price discrimination on the aggregate quantity is ambiguous in sign. Pigou (1920) found that aggregate quantities are unchanged by the third-degree price discrimination under the conditions of linear and independent demands. In our setting, if the demands are linear in prices, then $\kappa_{L}=0$ and $(25 \mathrm{~b})$ becomes

$$
\frac{d D}{d \phi}=-\frac{(1-\alpha) v C^{\prime}}{2 \Omega}
$$

By using (26) and noting $\alpha \in[0,1], v \geq 0, C^{\prime}>0$ and $\Omega>0$, we obtain:

Proposition 1 Assuming that the business and leisure demands are linear in prices:

(i) Price discrimination will always increase the business price; it will reduce the leisure price if the business and leisure passengers have identical or similar time valuations (in the sense that $\left.(1-\alpha) v<-2 B_{L}^{\prime \prime} / C^{\prime}\right)$, but will increase the leisure price if they have sufficiently distinct time valuations.

(ii) Pigou's (1920) result (that aggregate quantity is unchanged by the third-degree price discrimination with independent demands in prices) continues to hold for 
interdependent demands across the markets (i.e., $v>0$ ) as long as the business and leisure passengers have the same time valuation (i.e., $\alpha=1$ ). For distinct time valuations (i.e., $\alpha<1$ ) however, price discrimination will reduce the aggregate quantity.

Together, these two results complement and extend Pigou's (1920) result, and they will be useful in our welfare analysis (next subsection). Note that the result in the second part of Proposition 1 (that an increase in price discrimination reduces the aggregate quantity) may not hold when the demands are non-linear. Specifically, we will show, in Appendix $\mathrm{C}$, that an increase in price discrimination can be associated with greater aggregate quantity when the demands are convex. Furthermore, if the aggregate demand is sufficiently convex in the leisure price, an increase in price discrimination reduces both the leisure and business prices (Appendix $\mathrm{C}$ provides such an example).

A central result derived by, e.g., Holmes (1989) and Aguirre et al. (2010) shows that an increase in price discrimination is associated with an increase in price in the strong market (corresponding to the business market in our setting) and a price reduction in the weak market (corresponding to the leisure market). Nahata et al. (1990) show that both prices can move in the same direction when the profit function in at least one market is not single peaked. In the present paper with interdependent demands, prices in all markets can however be increasing or decreasing by price discrimination even though each market's profits are concave in own prices, which clearly shows the significance of demand interdependencies. Furthermore, this complements Layson's (1998) finding that demand substitution or falling marginal costs may be required for all prices to move in the same direction, since in our model marginal carrier costs are normalized to zero and the business and leisure passengers' benefits $B_{B}$ and $B_{L}$, respectively, are separable. ${ }^{12}$ 


\subsection{Welfare}

Regarding the welfare effect of price discrimination, it is well known that the first-best welfare result cannot be reached under the third-degree price discrimination when the demands are independent across the markets (i.e., $v=0$ in our setting). We now extend this well-known result to the case where demands are interdependent because of congestion externalities $(v>0)$. In our setting social welfare is simply the aggregate passenger benefits less total congestion costs (noting that $q=D$ ):

$$
W \equiv B_{B}+B_{L}-D \bar{v} C
$$

where

$$
\bar{v} \equiv \frac{\left(q_{B}+\alpha q_{L}\right) v}{q}
$$

is the arithmetic mean of passengers' time valuations, which will be referred to as the average time valuation (or, the inframarginal passengers' time valuation).

Proposition 2 Assuming that the demands are interdependent across markets (i.e., $v>0$ ) and the business passengers have a higher time valuation than the leisure passengers (i.e., $\alpha<1$ ), then (i) the first-best welfare result cannot be reached under laissez-faire, and (ii) the first-best price is uniform and given by $p^{*}=D \bar{v} C^{\prime}$, which is the external part of marginal congestion costs (recall that marginal cost has been normalized to zero).

Proof. (i) The welfare-optimal prices, denoted $p_{B}^{*}$ and $p_{L}^{*}$, are determined by the first-order conditions $\partial W / \partial p_{B}=0$ and $\partial W / \partial p_{L}=0$ or equivalently,

$$
D_{B}^{B} p_{B}^{*}+D_{B}^{L} p_{L}^{*}=D \bar{v} C^{\prime} D_{B} \text { and } D_{L}^{B} p_{B}^{*}+D_{L}^{L} p_{L}^{*}=D \bar{v} C^{\prime} D_{L}
$$

Since, by (5), (6) and (8), $D_{B}^{B} D_{L}^{L}-D_{L}^{B} D_{B}^{L}=1 / \Omega>0$, there exists a unique solution for $p_{B}^{*}$ and $p_{L}^{*}$ in (29). Applying Cramer's rule to the two equations and manipulating the terms lead to:

$$
p_{B}^{*}=\left(D_{B} D_{L}^{L}-D_{L} D_{B}^{L}\right) D \bar{v} C^{\prime} \Omega \text { and } p_{L}^{*}=\left(D_{L} D_{B}^{B}-D_{B} D_{L}^{B}\right) D \bar{v} C^{\prime} \Omega .
$$


It follows, from $D_{x}^{B}+D_{x}^{L}=D_{x}$, that $p_{B}^{*}=p_{L}^{*}$, i.e., a uniform price is required to achieve the first-best result.

(ii) From part (i), use $p^{*}$ to denote the welfare-optimal uniform price, i.e. $p_{B}^{*}=$ $p_{L}^{*}=p^{*}$. The first-order conditions in (29) can then be rewritten as

$$
\left(p^{*}-D \bar{v} C^{\prime}\right) D_{x}=0,
$$

which leads, by $D_{x}<0$ for $x=B, L$, to $p^{*}=D \bar{v} C^{\prime}$. That is, the welfare-optimal uniform price is equal to the external part of the marginal congestion costs.

Czerny and Zhang (2011) have already shown that a uniform price leads to the first-best solution when there are business and leisure passengers with distinct time valuations. ${ }^{13}$ The economic intuition for this result is as follows. Since a passenger's congestion effect on the other passengers is independent of his or her own time valuation, the congestion externality to be internalized by prices is independent of the passenger types. Specifically, the marginal congestion costs are $v C+q v C^{\prime}$ for business passenger and $\alpha v C+q v C^{\prime}$ for leisure passengers. Each of the first terms is part of the corresponding full fares of business or leisure passengers, and is therefore internalized by passengers, while the second part, $q \bar{v} C^{\prime}$, is not internalized and forms the external part of marginal congestion costs. This second part should thus be internalized at the welfare maximum. Furthermore, the welfare-optimal price, $p^{*}=D \bar{v} C^{\prime}$, shows that the welfare maximizer is concerned about the average time valuations. This is consistent with the findings of Spence (1975) and Sheshinski (1976), who found that the welfare maximizer is concerned about average "quality" valuations. Finally, we note that at $p^{*}=D \bar{v} C^{\prime}$, the welfare-optimal "full fares" are discriminating however: $p^{*}+v C$ for the business passengers and $p^{*}+\alpha v C$ for the leisure passengers. In other words, the discriminating full fares are required to reach the first-best solution.

\subsection{The time-valuation effect on welfare}

Schmalensee (1981) distinguishes between the misallocation and output effects of the third-degree price discrimination. The misallocation effect results from strict price 
discrimination, while the output effect is related to the fact that the monopoly prices typically exceed the welfare-optimal prices. In our scenario with congestion externality, there is a third source for market failure that is related to time valuations. To separate these effects and complement Schmalensee's (1981) approach, we take the derivative of welfare with respect to price discrimination, expand the derivative by adding and deducting $D \widehat{v} C^{\prime} d D / d \phi$ and rearrange to obtain

$$
\frac{d W}{d \phi}=\underbrace{\left(p_{B}-p^{u}\right) \frac{d D^{B}}{d \phi}+\left(p_{L}-p^{u}\right) \frac{d D^{L}}{d \phi}}_{\text {Misallocation effect }}+\underbrace{\left(p^{u}-D \widehat{v} C^{\prime}\right) \frac{d D}{d \phi}}_{\text {Output effect }}-\underbrace{(\bar{v}-\widehat{v}) D C^{\prime} \frac{d D}{d \phi}}_{\text {Time-valuation effect }}
$$

where the uniform price is evaluated at the uniform monopoly price and

$$
\widehat{v} \equiv \frac{\left(q_{B}^{\prime}+\alpha q_{L}^{\prime}\right) v}{q^{\prime}}
$$

Note that $\widehat{v}$ is defined as the average of the incremental passengers' time valuations and hence will be referred to as the marginal time valuation.

There are three bracketed terms on the RHS of that describe, respectively, the misallocation, output and time-valuation effects of price discrimination. The first two effects in (32) are familiar. With independent demands $(v=0)$, both terms of the misallocation effect are negative in sign, which shows that the misallocation effect is clear-cut and negative in that scenario. Notice that this effect can extend to our scenario with interdependent demands. In particular, when the demands are linear and the business and leisure passengers have similar time valuations, we have $p_{L}<p<p_{B}$ by Proposition 1 and consequently both misallocation-effect terms are negative. Proposition 1 also has implications for the sign of the output effect: The output effect is clear-cut and negative in sign when the demands are linear in prices, since an increase in price discrimination reduces the aggregate passenger quantity in this situation.

Our contribution to this welfare analysis lies in the introduction of the time-valuation effect, which appears as the last term on the RHS of (32). The effect depends on both $d D / d \phi$ (impact of price discrimination on aggregate quantities) and $\bar{v}-\widehat{v}$, the difference between the average and marginal time valuations. It is clear that $\bar{v}=\widehat{v}$ when either 
$v=0$ or $\alpha=1 .{ }^{14}$ Thus, the time-valuation effect won't exist if the demands are independent, or if the business and leisure passengers have the same time valuation. The following insight is useful to identify the sign of the time-valuation effect.

Remark 1 The elasticity condition implies $\widehat{v}<\bar{v}$, i.e., the marginal time valuation is lower than the average time valuation.

To see this, substitute $\left(1-q_{L}^{\prime} / q^{\prime}\right)$ for $q_{B}^{\prime} / q^{\prime}$ and $\left(1-q_{L} / q\right)$ for $q_{B} / q$, which can be used to show that for $q_{B}, q_{L}>0, \widehat{v}<\bar{v}$ when $q_{L}^{\prime} / q^{\prime}>q_{L} / q$, where the latter is implied by the elasticity condition.

With $\widehat{v}<\bar{v}$, (32) reveals that the time-valuation effect works to the opposite direction relative to the output effect. Intuitively, when the marginal time valuation is assumed to be lower than the average time valuation, an increase in price discrimination can potentially improve social welfare even when this is associated with a reduction in aggregate quantities (i.e., when $d D / d \phi<0$ ). This is because, as shown below, the carrier's decision is concerned with the marginal passengers' time valuations, which can lead to an excessively high aggregate quantity from the social viewpoint. Specifically, (32) can be used to show that price discrimination improves social welfare (i.e., $d W / d \phi>0)$ for $d D / d \phi<0$ if

$$
(\bar{v}-\widehat{v}) D C^{\prime}>\left(\left(p_{B}-p^{u}\right) \frac{d D^{B}}{d \phi}+\left(p_{L}-p^{u}\right) \frac{d D^{L}}{d \phi}\right)\left(\frac{d D}{d \phi}\right)^{-1}+\left(p^{u}-D \widehat{v} C^{\prime}\right) .
$$

The LHS of the inequality shows the difference between the external marginal congestion costs when average or marginal time valuations are used for evaluation. This term measures the carrier's incentives for the internalization of congestion costs and may therefore be described as the "internalization shortfall." The first term on the RHS captures the misallocation effect (or, more precisely, the loss in welfare associated with misallocation per reduced passenger). The second term shows the carrier's markup on the marginal external congestion costs evaluated at marginal time valuation. Clearly, if the aggregate passenger demand is inelastic and mark-ups are sufficiently high, congestion may be no problem and the time-valuation effect will be dominated 
by the output effect. Altogether, price discrimination and a reduction in the aggregate passenger quantity improves welfare only if the incentives to internalize congestion are low relative to the welfare-loss associated with misallocation and the mark-up on marginal external congestion costs evaluated at marginal time valuations. This is in sharp contrast to the existing result that price discrimination can improve welfare only if it is associated with an increase in aggregate quantities (e.g., Schmalensee, 1981, and Varian, 1985).

The above discussion leads to:

Proposition 3 Price discrimination by a monopoly carrier can, while reducing aggregate output, improve social welfare if the time valuations between the business and leisure passengers are sufficiently distinct in the sense described implicitly by the inequality (34).

The congestion inefficiency under uniform monopoly pricing can be understood as follows. Under uniform pricing $(\phi=0)$, the carrier's first-order condition (17) can be rewritten as

$$
p^{u}=-D /\left(D_{L}+D_{B}\right)
$$

Using (9), $B_{L}^{\prime \prime}=1 / q_{L}^{\prime}$ and $B_{B}^{\prime \prime}=1 / q_{B}^{\prime}$, the above expression can be manipulated to become:

$$
p^{u}=q \widehat{v} C^{\prime}-q / q^{\prime}
$$

It can be seen (after rearranging the terms in (36)) that in this case, the carrier chooses a markup on the external marginal congestion costs evaluated at marginal time valuation $\widehat{v}^{15}$ If this markup satisfies

$$
\bar{v}-\widehat{v}=-1 /\left(q^{\prime} C^{\prime}\right)
$$

then uniform price $p^{u}$ is just equal to the external part of the marginal congestion costs, i.e., $p^{u}=p^{*}$. The uniform monopoly price is therefore socially optimal if condition (37) holds. Since the RHS of (37) is strictly positive, a necessary condition for the monopoly 
behavior to be socially optimal is $\widehat{v}<\bar{v}$, i.e., the marginal time valuations are small relative to the average time valuations.

What happens if the time valuations are too distinct, in the sense that $\bar{v}-\widehat{v}>$ $-1 /\left(q^{\prime} C^{\prime}\right)$ ? Then, $p^{u}<p^{*}$ : With the uniform monopoly price being too low from the social viewpoint, excessive congestion occurs. This is why price discrimination can have a positive effect on social welfare although the first-best result can never be achieved with discriminating prices. By reducing the aggregate quantity, price discrimination reduces congestion costs and may actually improve welfare, relative to uniform pricing, when such a positive effect outweighs the negative output and misallocation effects. Here, price discrimination in a sense serves as the "second best" solution to the problem.

\section{Examples}

Consider passenger benefits in the quadratic form of

$$
B_{B}=a_{B} q_{B}-\frac{q_{B}^{2}}{2} \text { and } B_{L}=a_{L} q_{L}-b \frac{q_{L}^{2}}{2}
$$

with $a_{x}>0, b>0$ and $x=B, L$, and average delays are in the linear form of $C=q$. Many of the results derived in this paper are related to the time-valuations difference between the business and leisure passengers. For a given value of $v$, this difference is maximized when $\alpha=0$ (i.e., leisure time valuations are zero), which will be assumed in the following instances. The analytical solutions for the uniform and laissez-faire prices are provided in Appendix B (for $\alpha=0$ ). This appendix further derives the analytical solutions for the misallocation, output and time-valuation effects of third-degree price discrimination as described by (32). Letting $W$ with $W \equiv W(\phi)$ denote welfare depending on the price-difference constraint and using (32), the difference between welfares under uniform and discriminating prices can be calculated as

$W\left(\phi^{l f}\right)-W(0)=\int_{0}^{\phi^{l f}}\left(\left(p_{B}-p^{u}\right) d D^{B}+\left(p_{L}-p^{u}\right) d D^{L}\right)+\int_{0}^{\phi^{l f}}\left(p^{u}-D \widehat{v} C^{\prime}\right) d D-\int_{0}^{\phi^{l f}}(\bar{v}-\widehat{v}) D C^{\prime} d D$. 
The first term on the RHS is called the cumulated misallocation effect, the second term the cumulated output effect and the third term the negative of the cumulated time-valuation effect.

Output effect dominant The first parameter instance with $a_{B}=4, a_{L}=1$ and $b=1 / 10$ implies that the output effect dominates the time-valuation effect for the relevant parameter ranges $(v<3 / 4$ ensures that the elasticity condition is satisfied), which is true in the sense that the cumulated output effect exceeds the cumulated time-valuation effect in absolute values. ${ }^{16}$ Figure 2 illustrates this scenario. The aggregate effect (solid line) shows how discriminating prices change welfare relative to uniform prices depending on time valuations. The welfare change can be split up in the (cumulated) misallocation, output and time-valuation effects (dashed lines). Since price discrimination reduces the aggregate quantity relative to uniform pricing when demands are linear and the output effect dominates, discriminating prices clearly reduce welfare relative to uniform prices. Note that the output and time-valuation effects are zero for $v=0$. This is because demands are linear and independent, when time valuations are zero, which means that Pigou's (1920) result applies and the aggregate quantity is independent of whether prices are uniform or discriminating. Furthermore, for $v=3 / 4$ all effects are zero because business and leisure prices are the same under these conditions.

Figure 2

Time-valuation effect dominant Consider a second parameter instance, which is identical to the previous one except that the business passengers' maximum reservation price is now $a_{B}=6$ instead of $a_{B}=4$. This parameter instance is special in the sense that the monopoly profit is strictly higher when prices are discriminating than when the leisure market is abandoned for $v<1 / 2$, while these profits are just the same when $v=1 / 2{ }^{17}$ Furthermore, the scenario with uniform prices is a local optimum because the carrier would be better off by abandoning the leisure market when $v \leq 1 / 2$, and 
in this local optimum the aggregate quantity is high relative to the aggregate quantity when prices are discriminating. Still, welfare is increased by price discrimination relative to uniform prices (when all markets are covered) when business time-valuations are sufficiently high $(v \geq 0.46)$, which is due to the time-valuation effect. Thus, discriminating fares are preferred from the carrier's and the social viewpoint under these conditions due to the time-valuation effect. Figure 3 illustrates this scenario.

\section{Figure 3}

\section{Concluding Remarks}

Our main objective in writing this paper is to contribute to the literature on price discrimination. We have considered a monopoly carrier and analyzed third-degree price discrimination in the presence of congestion externality. A crucial feature in our analysis is that the passengers' full fares are composed of the (ticket) prices and congestion costs. Changes in a market's price therefore have a direct effect on its own full fare, and an indirect effect on all the full fares through a change in the aggregate passenger quantity and thus congestion delays. We found that the important result obtained by earlier researchers that price discrimination is associated with a price increase in the strong market (corresponding to the business market in our setting) and a price reduction in the weak market (corresponding to the leisure market) when each market's profits is concave in own prices, continues to hold as long as the demand interdependence (through congestion externality) is sufficiently small, or the business and leisure passengers have similar values of time. However, if the time valuations are sufficiently distinct, then price discrimination can raise prices in all markets under linear demands. Convex leisure demands were used to show that, price discrimination can also reduce prices in all markets relative to a situation with uniform prices. Furthermore, we found that social welfare can be increased by price discrimination even if the aggregate passenger quantity is reduced. This is because the output effect of price discrimination and the "time-valuation effect," which we identified in this paper, work in opposite 
directions.

This analysis provides several avenues for future research. First and foremost, note that changes in prices are not directly informative with respect to changes in quantities because quantities depend on full fares in our setup and prices determine only one part of the full fares, while the other part is determined by congestion costs. For example, an increase in price discrimination, which leads to an increase in the business price and a reduction in the aggregate passenger quantity can reduce the business full fare and thus increase the business quantity. To derive an understanding of how price discrimination affects passenger quantities it would therefore be useful to analyze the effect of price discrimination on full fares and full-fare discrimination (recall that discriminating are required to implement the first-best solution). Furthermore, a useful extension would be to consider interdependent markets with positive externalities (as opposed to the negative congestion externality considered in this paper) which may arise in, for example, media, software and telecommunication markets. Another natural problem, which is addressed in a companion paper (Czerny and Zhang, 2013), is to analyze facility congestion and third-degree price discrimination when carriers compete in quantities a la Cournot. This companion paper shows that the socially efficient airport charge can be substantially higher than what we learned from the recent literature on congestion pricing with non-atomistic airlines whether ticket prices are uniform or discriminating. 


\section{References}

Adachi, Takanori (2005) "Third-degree price discrimination, consumption externalities and social welfare." Economica 72, 171-178

Aguirre, Inaki, Simon Cowan and John Vickers (2010) "Monopoly Price Discrimination and Demand Curvature." American Economic Review 100, 1601-1615

Borenstein, Severin (1985) "Price Discrimination in Free-entry Markets." RAND Journal of Economics 16, 380-397

Brueckner, Jan K. (2002) "Airport Congestion When Carriers Have Market Power." American Economic Review 92, 1357-1375

Chen, Yongmin and Marius Schwartz (2013) "Differential Pricing When Costs Differ: A Welfare Analysis." Georgetown University, Department of Economics Working Paper 1301, April 2013. <http://www8.georgetown.edu/departments/economics/pdf/1301.pdf>

Cowan, Simon (2013) "Welfare-increasing Third-degree Price

Discrimination." Unpublished working paper downloadable at: http://users.ox.ac.uk/ econsgbc/LogisticWelfare.pdf

Cowan, Simon (2012) "Third-degree Price Discrimination and Consumer Surplus." Journal of Industrial Economics 60, 333-345

Cowan, Simon (2007) "The Welfare Effects of Third-degree Price Discrimination with Nonlinear Demand Functions." RAND Journal of Economics 38, 419-428

Czerny, Achim I. and Anming Zhang (2011) "Airport Congestion Pricing and Passenger Types." Transportation Research Part B: Methodological 45, 595-604

Czerny, Achim I. and Anming Zhang (2014) "Airport Congestion Pricing when Airlines Price Discriminate." Transportation Research Part B: Methodological 65, 77-89 
Dana, J. D. (1998), Advance-purchase discounts and price discrimination in competitive markets, Journal of Political Economy, 2: 395-422.

Dana, James D. (1999a) "Using Yield Management to Shift Demand When the Peak Time is Unknown." RAND Journal of Economics 30, 456-474

Dana, James D. (1999b) "Equilibrium Price Dispersion Under Demand Uncertainty: The Roles of Costly Capacity and Market Structure." RAND Journal of Economics $30,632-660$

Daniel, Joseph I. (1995) "Congestion Pricing and Capacity of Large Hub Airports: A Bottleneck Model with Stochastic Queues." Econometrica 63, 327-370

Gale, Ian L. and Thomas J. Holmes (1993) "Advance-purchase Discounts and Monopoly Allocation of Capacity." American Economic Review 83, 135-146

Glass, Amy J. (2001) "Price Discrimination and Quality Improvement." Canadian Journal of Economics / Revue canadienne d'Economique 34, 549-569

Hausman, Jerry A. and Jeffrey K. MacKie-Mason (1988) "Price Discrimination and Patent Policy." RAND Journal of Economics 19, 253-265

Hazledine, Tim (2006) "Price Discrimination in Cournot-Nash Oligopoly." Economics Letters 93, 413-420

Holmes, Thomas J. (1989) "The Effects of Third-degree Price Discrimination in Oligopoly." American Economic Review 79, 244-250

Layson, Stephen K. (1994), Third-degree price discrimination under economies of scale, Southern Economic Journal, 61: 323-327.

Layson, Stephen K. (1998) "Third-degree Price Discrimination with Interdependent Demands." Journal of Industrial Economics 46, 6511-6524 
Lazarev, John (2013) "The Welfare Effects of Intertemporal Price Discrimination: An Empirical Analysis of Airline Pricing in U.S. Monopoly Markets." Mimeo, Graduate School of Business, Stanford University

Leontief, Wassily (1940) "The Theory of Limited and Unlimited Discrimination." Quarterly Journal of Economics 50, 490-501

Mayer, Christoph and Todd Sinai (2003) "Network Effects, Congestion Externalities, and Air Traffic Delays: Or Why Not All Delays are Evil." American Economic Review 93, 1194-1215

Morrison, Steven A. (1987) "The Equity and Efficiency of Runway Pricing." Journal of Public Economics 34, 45-60

Morrison, Steven A. and Clifford Winston (1989) "Enhancing the Performance of the Deregulated Air Transportation System." Brookings Papers on Economic Activity: Microeconomics, 61-123.

Morrison, Steven A. and Clifford Winston (2007) "Another Look at Airport Congestion Pricing." American Economic Review 97, 1970-1977

Nahata, Babu, Krzysztof Ostaszewski and P. K. Sahoo (1990) "Direction of Price Changes in Third-degree Price Discrimination." American Economic Review 80, 12541258

Niskanen, Esko (1987) "Congestion Tolls and Consumer Welfare." Transportation Research Part B 21B, 171-174

Pels, Eric, Peter Nijkamp and Piet Rietveld (2003) "Access to and Competition Between Airports: A Case Study for the San Francisco Bay Area." Transportation Research Part A: Policy and Practice 37, 71-83

Pigou, Arthur C. (1920), The Economics of Welfare, London: Macmillan.

Robinson, Joan (1933), The Economics of Imperfect Competition, Macmillan, London. 
Schmalensee, Richard (1981) "Output and Welfare Implications of Monopolistic Thirddegree Price Discrimination." American Economic Review 71, 242-247

Schwartz, Marius (1990) "Output and Welfare Effects of Monopolistic Third-degree Price Discrimination." American Economic Review 80, 870-875

Sheshinski, Eytan (1976) "Price, Quality and Quantity Regulation in Monopoly." Economica 43, 127-137

Spence, A. Michael (1975) "Monopoly, Quality and Regulation." Bell Journal of Economics 6, 417-429

Stavins, Joanna (2001) "Price Discrimination in the Airline Market: The Effect of Market Concentration." Review of Economics and Statistics 83, 200-202

Stole, Lars A. (2007) "Price Discrimination and Competition," in Handbook of Industrial Organization Vol. 3, ed. M. Armstrong and Robert H. Porter (Amsterdam: North-Holland)

USDOT (1997) "The Value of Saving Travel Time: Departmental Guidance for Conducting Economic Evaluations." US Department of Transportation, Washington, DC. Varian, Hal R. (1985) "Price Discrimination and Social Welfare." American Economic Review 75, 870-875

Yoshida, Yoshihiro (2000) "Third-degree Price Discrimination in Input Markets: Output and Welfare." American Economic Review 90, 240-246

Yuen, Andrew C. L. and Anming Zhang (2011) "Airport Congestion Pricing and Its Welfare Implications: The Case of Variable Passenger Time Costs." Pacific Economic Review 16, 83-102

Zhang, Anming and Achim I. Czerny (2012) "Airports and Airlines Economics and Policy: An Interpretive Review of Recent Research." Economics of Transportation 1, 15-34 
Zhang, Anming and Yimin Zhang (2006) "Airport Capacity and Congestion When Carriers Have Market Power." Journal of Urban Economics 60, 229-247 
Lead footnote: In writing this paper, we have incurred substantial debt to Jan Brueckner for his many constructive and detailed comments and suggestions. We also thank Simon Cowan for his comments and especially for his comprehensive remarks on the related literature. Comments by two annonymous referees have also led to a marked improvement of our paper. Finally, we thank Amihai Glazer, Erik Verhoef and seminar participants at University of Rome "La Sapienza" for helpful comments and suggestions. Partial financial support from the Social Science and Humanities Research Council of Canada (SSHRC) and the European Research Council (ERC, AdG Grant \#246969 OPTION) is gratefully acknowledged.

\section{Notes}

${ }^{1}$ Lazarev (2013) finds that leisure passengers typically start searching for a ticket at least six weeks prior to departure, while business passengers typically search in the last week. Furthermore, he finds that business demands are significantly less price elastic than leisure demands.

${ }^{2}$ Indirect utilities are not necessarily convex in prices when congestion externalities are involved. Niskanen (1987) considers road traffic and shows that consumer welfare can be increasing in toll when travelers have distinct time valuations.

${ }^{3}$ This is shown under linear demands, where prices can rise but cannot fall in both markets. Prices can however fall in both markets when demands are convex as is shown in Appendix C. Note that these results hold true even if each market's profits are concave in own prices; thus, these findings complement the analysis provided by Nahata et al. (1990).

${ }^{4}$ While quality supply is directly determined by prices in the present paper, Glass (2001) analyzes an environment where prices and quality supplies are independent strategic variables.

${ }^{5}$ Other examples for markets where price discrimination increases social welfare when aggregate outputs are reduced by price discrimination are input markets (Yoshida, 2000).

${ }^{6}$ Hazledine (2006) is an exception. He considers an arbitrary number of identical airlines that compete in quantities a la Cournot. His model uses linear functional forms and abstracts away from congestion. He finds that the average price may be independent of the number of fare classes.

${ }^{7}$ Czerny and Zhang (2014) use the same elasticity condition in the context of oligopolistic carrier markets. That $p_{B}^{l f} \geq p_{L}^{l f}$ may, in the airline industry, be also justified by such practices as advancedpurchase rebates for leisure passengers. To abstract away from self selection, assume that the cost of 
early booking is prohibitive for business passengers.

${ }^{8}$ Substitute $q_{B}^{\prime}+q_{L}^{\prime}$ for $q^{\prime}$ and $q_{B}+q_{L}$ for $q$, in order to rewrite the inequality $-q_{L}^{\prime} / q_{L}>-q^{\prime} / q$ as $-q_{L}^{\prime} / q_{L}>-\left(q_{B}^{\prime}+q_{L}^{\prime}\right) /\left(q_{B}+q_{L}\right)$. Rearranging yields $\left(q_{L} q_{B}^{\prime}-q_{L}^{\prime} q_{B}\right) / q_{L}\left(q_{B}+q_{L}\right)>0$, where the LHS is positive by the elasticity condition.

${ }^{9}$ Price-difference constraints have been used by, for example, Leontief (1940), Schmalensee (1981), Holmes (1989) and Aguirre et al. (2010).

${ }^{10}$ Section 4 describes the specific functional forms used to derive this example.

${ }^{11}$ It can be calculated that $\pi^{\prime \prime}=2\left(D_{L}+D_{B}\right)+p \cdot\left(D_{L L}^{L}+2 D_{L B}^{L}+D_{B B}^{L}\right)+(p+\phi) \cdot\left(D_{L L}^{B}+2 D_{B L}^{B}+D_{B B}^{B}\right)$. Thus, $\pi^{\prime \prime}<0$ when the demands are linear in prices.

${ }^{12}$ Specfically, benefits are additively separable in our scenario, since benefits $B_{x}$ are fully independent of $q_{y}$ with $y \neq x$. This means that business and leisure demands in full fares are independent of each other, while Layson (1998) concentrates on scenarios, where goods are substitutes or complements in the sense that an increase in the consumption of one good decreases or increases the demand of the other good. Since Layson abstracts away from externalities, prices correspond to "full fares" in his setup.

${ }^{13}$ But the possibility of carrier price discrimination is abstracted away in their analysis.

${ }^{14}$ For the average and marginal time valuations it holds that $\bar{v}, \widehat{v} \leq v$. Both are, as expected, increasing in the leisure passengers' time valuation, that is, $\partial \bar{v} / \partial \alpha$ and $\partial \widehat{v} / \partial \alpha>0$. The average and marginal time valuations are clearly the same when the business and leisure markets are independent (i.e., $v=0$ ), or when the business and leisure passengers have the same time valuations (i.e., when $\alpha=1)$.

${ }^{15}$ This is consistent with the finding of Yuen and Zhang (2011).

${ }^{16}$ This parameter instance further implies that business and leisure quantities are strictly positive in the global optimum, which is independent of whether prices are uniform or discriminating.

${ }^{17}$ In this instance, the non-negativity constraint for the leisure quantity becomes binding for $v \geq 1 / 2$ when prices are discriminating. 


\section{Appendix}

\section{A Laissez-faire Prices}

The laissez-faire prices are implicitly determined by the two first-order conditions in (15). By (5), (8) and (6),

$$
\operatorname{det}\left(\begin{array}{cc}
D_{L}^{L} & D_{L}^{B} \\
D_{B}^{L} & D_{B}^{B}
\end{array}\right)=1 / \Omega,
$$

which means that there exists a unique solution for $p_{B}^{l f}$ and $p_{L}^{l f}$. Applying Cramer's rule to the two first-order conditions and manipulating the terms lead to:

$$
\begin{aligned}
& p_{L}^{l f}=\operatorname{det}\left(\begin{array}{cc}
-D^{L} & D_{L}^{B} \\
-D^{B} & D_{B}^{B}
\end{array}\right) \Omega=\left(D^{B} D_{L}^{B}-D^{L} D_{B}^{B}\right) \Omega \\
& p_{B}^{l f}=\operatorname{det}\left(\begin{array}{cc}
D_{L}^{L} & -D^{L} \\
D_{B}^{L} & -D^{B}
\end{array}\right) \Omega=\left(D_{B}^{L} D^{L}-D^{B} D_{L}^{L}\right) \Omega,
\end{aligned}
$$

where the first terms on RHSs are always positive by (5)-(9), which means that the prices are positive in all markets. Furthermore, comparison of the prices and using the comparative-static results in (5) and (8) yields:

$$
p_{B}^{l f}>p_{L}^{l f} \Rightarrow \frac{B_{L}^{\prime \prime}}{D^{B}}>\frac{B_{B}^{\prime \prime}}{D^{L}}
$$

which is equivalent to the elasticity condition, since $q_{x}^{\prime}=1 / B_{x}^{\prime \prime}$ for $x=B, L$.

\section{B Linear Demands}

With benefits in (38), the demands can be expressed as,

$$
\begin{aligned}
D^{L}(p, p+\phi) & =\frac{\left(a_{L}-p\right)}{b} \\
D^{B}(p, p+\phi) & =\frac{\left(a_{B}-p-\phi\right) b-\left(a_{L}-p\right) v}{b(1+v)} .
\end{aligned}
$$


It can be easily seen that the leisure demand is downward-sloping in the leisure price, while an increase in the leisure price can increase the business demand. Furthermore, the carrier's optimal prices can be explicitly obtained:

$$
p_{L}(\phi)=\frac{a_{L}+a_{B} b-(2 b-v) \phi}{2(1+b)}
$$

and

$$
p_{B}(\phi)=\frac{a_{L}+a_{B} b+(2+v) \phi}{2(1+b)},
$$

which implies uniform prices

$$
p_{L}(0)=p_{B}(0)=\frac{a_{L}+a_{B} b}{2(1+b)} .
$$

Substituting the above solutions of $p_{L}$ and $p_{B}$ into aggregate demand $D=D^{L}+D^{B}$ and rearranging the terms leads to:

$$
D\left(p_{L}(\phi), p_{B}(\phi)\right)=\frac{a_{L}+a_{B} b-v \phi}{2 b(1+v)} .
$$

The derivative of $D$ with respect to $\phi$ is negative, which confirms Proposition $1 .{ }^{18}$ Moreover, (46) and (47) can be used to write the profit as a function of price discrimination represented by parameter $\phi$. While the uniform prices imply $\phi=0$, under the laissezfaire regime the carrier can choose $\phi$ to maximize its profit. Such laissez-faire prices are unique and given by $p_{L}(\phi)$ of (46) and $p_{B}(\phi)$ of $(47)$, with $\phi=\phi^{l f}$ determined by

$$
\begin{aligned}
\phi^{l f} & \equiv \arg \max _{\phi} p_{L}(\phi) D_{L}\left(p_{L}(\phi), p_{B}(\phi)\right)+p_{B}(\phi) D_{B}\left(p_{L}(\phi), p_{B}(\phi)\right) \\
& =\frac{\left(a_{L}(v+2 b(1+v))-a_{B}(2+v)\right) b}{v^{2}-4 b(1+v)}
\end{aligned}
$$

conditional on the covery of the business and the leisure market. This shows that the laissez-faire prices are highly nonlinear in the business time valuations $v$. To ensure that the elasticity condition is satisfied (i.e., $\phi^{l f} \geq 0$ ), assume that $a_{B} \geq$ $a_{L}(v+2 b(1+v)) /(b(2+v))$. Laissez-faire prices can then be derived as

$$
p_{L}\left(\phi^{l f}\right)=\frac{a_{L}\left(v^{2}-2 b(1+v)\right)-a_{B} b v}{v^{2}-4 b(1+v)}
$$


and

$$
p_{B}\left(\phi^{l f}\right)=p_{L}\left(\phi^{l f}\right)+\phi^{l f}=\frac{\left(a_{L} v-2 a_{B} b\right)(1+v)}{v^{2}-4 b(1+v)} .
$$

Furthermore, following the definition of the misallocation, output and time-valuation effects in (32), these effects can be calculated as:

$$
\begin{aligned}
& \left(p_{L}(\phi)+\phi-p_{L}(0)\right) \frac{\partial D^{B}\left(p_{L}(\phi), p_{B}(\phi)\right)}{\partial \phi}+\left(p_{L}(\phi)-p_{L}(0)\right) \frac{\partial D^{L}\left(p_{L}(\phi), p_{B}(\phi)\right)}{\partial \phi} \\
= & \frac{\left(v^{2}-4 b(1+v)\right) \phi}{4 b(1+b)(1+v)}, \\
& \left(p_{L}(0)-\widehat{v} D\right) \frac{\partial\left(D^{L}\left(p_{L}(\phi), p_{B}(\phi)\right)+D^{B}\left(p_{L}(\phi), p_{B}(\phi)\right)\right)}{\partial \phi} \\
= & -\frac{v\left(a_{L}+a_{B} b+v^{2} \phi\right)}{4 b(1+b)(1+v)^{2}}
\end{aligned}
$$

and

$$
\begin{aligned}
& (\bar{v}-\widehat{v}) D \frac{\partial\left(D^{L}\left(p_{L}(\phi), p_{B}(\phi)\right)+D^{B}\left(p_{L}(\phi), p_{B}(\phi)\right)\right)}{\partial \phi} \\
= & \frac{v^{2}\left(a_{B} b(2+v)-a_{L}(v+2 b(1+v))+\left(v^{2}-2 b(1+v)\right) \phi\right)}{4 b^{2}(1+b)(1+v)^{2}},
\end{aligned}
$$

respectively, with $\widehat{v}=v b /(1+b)$. Finally, integrating (53), (54) and (55) yields the difference between welfares under uniform pricing and price discrimination that is associated with misallocation, changes in outputs and the difference in time valuations:

$$
\begin{aligned}
& \int_{0}^{\phi^{l f}} \frac{\left(v^{2}-4 b(1+v)\right) \phi}{4 b(1+b)(1+v)} d \phi=\frac{\left(a_{B} b(2+v)-a_{L}(v+2 b(1+v))\right)^{2}}{8 b(1+b)(1+v)\left(v^{2}-4 b(1+v)\right)} \\
& \int_{0}^{\phi_{f}^{l f}}-\frac{v\left(a_{L}+a_{B} b+v^{2} \phi\right)}{4 b(1+b)(1+v)^{2}} d \phi \\
= & -\frac{v\left(a_{B} b(2+v)-a_{L}(v+2 b(1+v))\right)\left(a_{B} b\left(v^{3}+8 b(1+v)\right)-a_{L}(2+v)\left(v^{2}-2 b(2-v)(1+v)\right)\right.}{8 b(1+b)(1+v)\left(v^{2}-4 b(1+v)\right)}
\end{aligned}
$$

and

$$
\begin{aligned}
& \int_{0}^{\phi^{l f}} \frac{v^{2}\left(a_{B} b(2+v)-a_{L}(v+2 b(1+v))+\left(v^{2}-2 b(1+v)\right) \phi\right)}{4 b^{2}(1+b)(1+v)^{2}} d \phi \\
= & \frac{v^{2}\left(6 b(1+v)-v^{2}\right)\left(a_{B} b(2+v)-a_{L}(v+2 b(1+v))\right)^{2}}{8 b(1+b)(1+v)\left(v^{2}-4 b(1+v)\right)},
\end{aligned}
$$


respectively.

\section{Convex Demand}

This section provides numerical examples showing that an increase in price discrimination can lead to a reduction of both the business and leisure prices. Here it is clear that the demands must be non-linear in full fares. More specifically, we assume that

$$
B_{L}=a_{L} q_{L}-\left(3 b_{L} q_{L}^{2 / 3} / 2\right)
$$

that is, the leisure demand is convex in full fares (i.e., $q_{L}^{\prime \prime}>0$, while $q_{B}^{\prime \prime}=0$ ). To maximize the difference in time valuations for given business passengers' time valuations $v$, the leisure passengers' time valuations are set to zero $(\alpha=0)$.

With this benefit specification, the demands can be written as

$$
\begin{aligned}
& D^{L}(p, p+\phi)=\max \left\{0, \frac{16\left(a_{L}-p^{2}\right)}{81 b_{L}^{2}}\right\} \\
& D^{B}(p, p+\phi)=\max \left\{0, \frac{\left(a_{B}-p-\phi\right)-v D^{L}(p, p+\phi)}{b_{B}+v}\right\} .
\end{aligned}
$$

These demands imply that $D_{L L}=32 b_{B} /\left(81 b_{L}^{2}\left(b_{B}+v\right)\right)$. The aggregate demand is hence convex in the leisure price. The monopoly leisure price becomes

$$
p_{L}(\phi)=\frac{32 a_{L} b_{B}+81 b_{L}^{2}+16 v \phi-\Delta}{48 b_{B}}
$$

with

$$
\Delta \equiv \sqrt{\left(32 a_{L} b_{B}+81 b_{L}^{2}+16 v \phi\right)^{2}-48 b_{B}\left(81 b_{L}^{2}\left(a_{B}-2 \phi\right)+16 a_{L}\left(a_{L} b_{B}+2 v \phi\right)\right)}
$$

for $D^{B}, D^{L}>0$ and $p_{B} \geq p_{L}>0$.

Consider parameter specifications $a_{B}=2, a_{L}=1, b_{B}=1 / 2, b_{L}=1 / 3$ and $v=1$. In

this instance, price discrimination under laissez faire is $\phi^{l f}=0.19$. Figure 4 displays the corresponding monopoly prices and shows that the uniform monopoly price is equal to one. As price discrimination increases, this leads, first, to a reduction of both the 
leisure and business prices, while for sufficiently high values of $\phi$, the business price rises. Thus, the change in the business price is not monotone in price discrimination. However, the business price is smaller in the laissez-faire scenario than the price under uniform pricing, that is, $p_{B}\left(\phi^{l f}\right)<p_{B}(0)$. To understand why the business price is reduced by price discrimination, note that a reduction in the leisure price is associated with a large increase in the leisure quantity, which increases congestion, increases the business full fares, reduces the business demands in ticket prices and thus the discriminating business price. Furthermore, welfare is increased by price discrimination because this increases the aggregate passenger quantity (see Figure 5) and because the output effect dominates the time-valuation effect (see Figure 6).

Figure 4

Figure 5

Figure 6 
Diagrams 


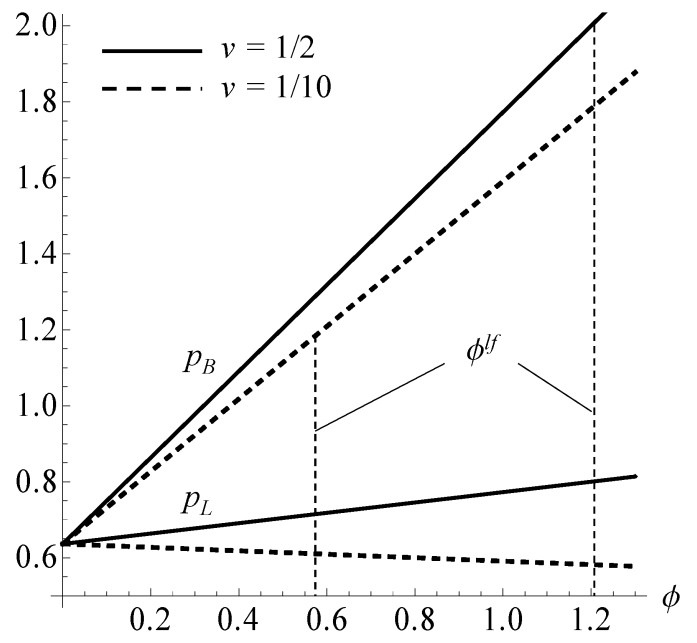

Figure 1: Prices depending on $\phi$. The solid lines describe a situation where time valuations are more distinct relative to the dashed lines. For the solid lines it holds $v=1 / 2$, while $v=1 / 10$ for the dashed lines. Other parameters are: $a_{B}=4, a_{L}=$ $1, b=1 / 10, \alpha=0$. 


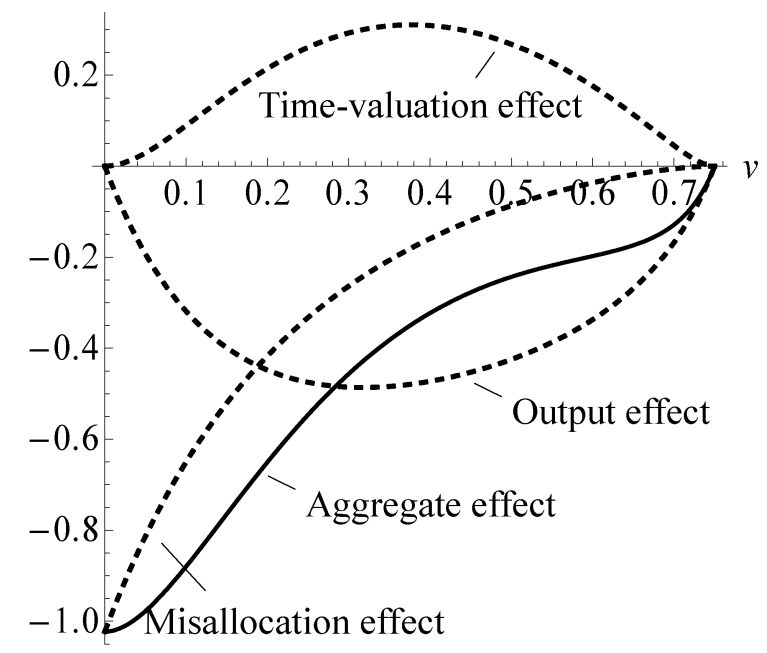

Figure 2: Discriminating prices reduce welfare relative to uniform prices: The aggregate effect (solid line) shows how a move from uniform pricing towards third-degree price discrimination changes welfare depending on the time-valuation of business passengers. The change in welfare can be split up in the cumulated misallocation, output and time-valuation effects (dashed lines). Parameters: $a_{B}=4, a_{L}=1, b=1 / 10$. 


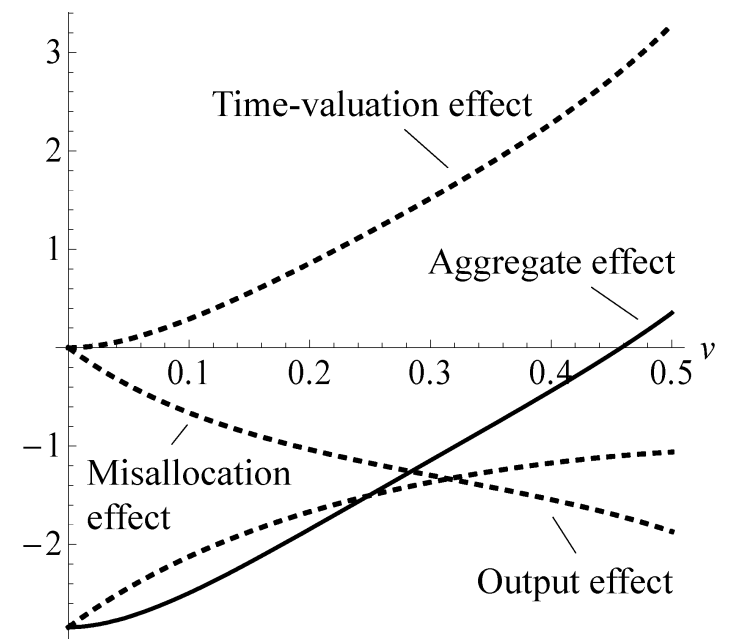

Figure 3: Discriminating prices can increase welfare relative to uniform prices when business time-valuations are sufficiently high: The aggregate effect (solid line) shows how a move from uniform pricing towards third-degree price discrimination changes welfare depending on the time-valuation of business passengers. The change in welfare can be split up in the cumulated misallocation, output and time-valuation effects (dashed lines). Parameters: $a_{B}=6, a_{L}=1, b=1 / 10$.

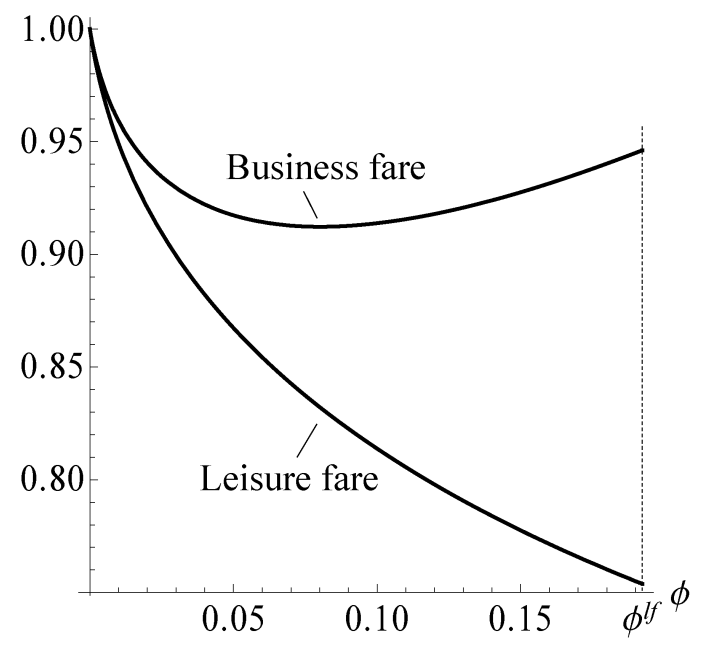

Figure 4: Fares when leisure demand is convex in the leisure price $\left(\phi^{l f}=0.19\right)$. Parameters: $a_{B}=2, a_{L}=1, b_{B}=1 / 2, b_{L}=1 / 3, v=1$. 


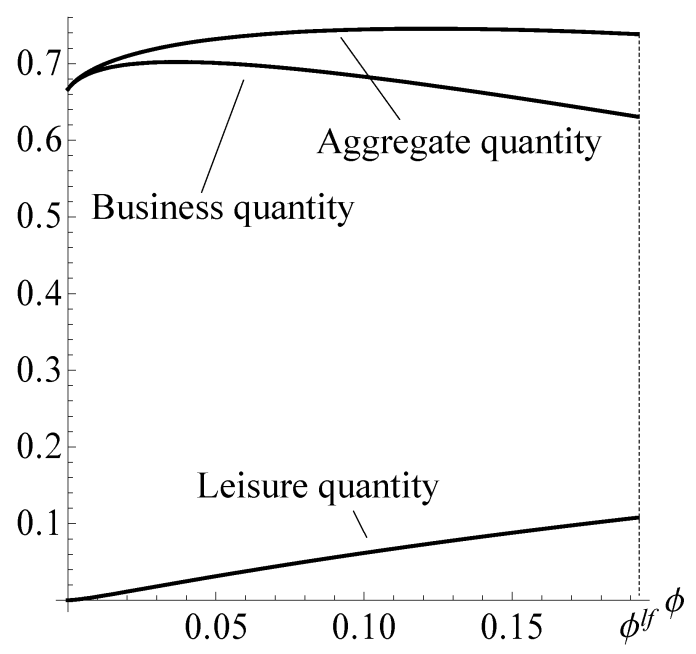

Figure 5: Quantities when leisure demand is convex in the leisure price $\left(\phi^{l f}=0.19\right)$. Parameters: $a_{B}=2, a_{L}=1, b_{B}=1 / 2, b_{L}=1 / 3, v=1$.

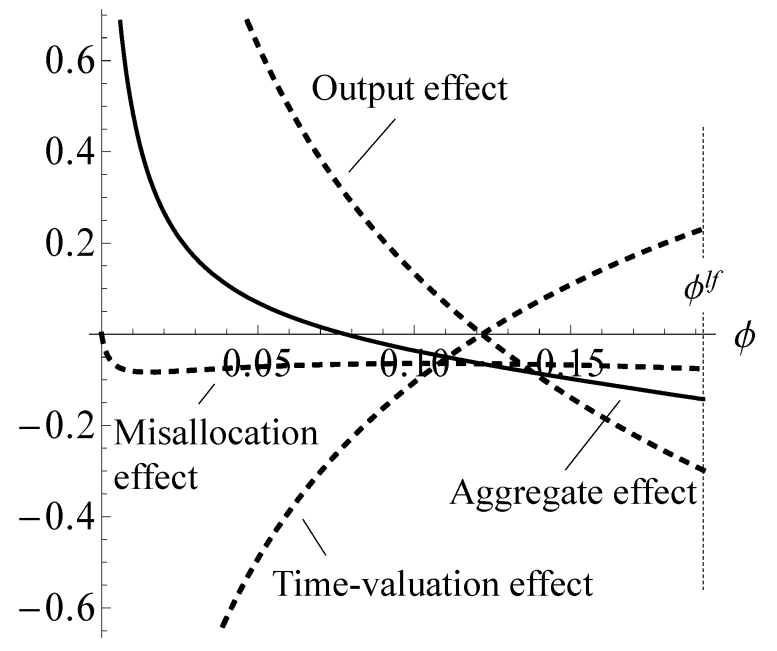

Figure 6: Misallocation, output and time-valuation effects when leisure demand is convex in the leisure ticket price $\left(\phi^{l f}=0.19\right)$. Parameters: $a_{B}=2, a_{L}=1, b_{B}=$ $1 / 2, b_{L}=1 / 3, v=1$. 